\title{
New immunological assays for the diagnosis of Helicobacter pylori infection
}

D Vaira, J Holton, M Menegatti, C Ricci, F Landi, A Ali', L Gatta, C Acciardi, S Farinelli, M Crosatti, S Berardi, M Miglioli

\begin{abstract}
Summary
There are several types of immunological tests available for the diagnosis and management of Helicobacter pylori infection. Most commercially available serological kits use the enzyme linked immunosorbent assay (ELISA) test format. Originally the kits used crude antigen preparations although many of the newer kits use a more purified antigen preparation, with often increased specificity but lower sensitivity. Near patient test kits are based either on latex agglutination or immunochromatography. Generally they have low sensitivities compared with laboratory tests. Western blotting, ELISA, and recombinant immunoblot assays (RIBA) have also been developed into commercially available kits and can be used to indicate the presence of specific virulence markers. An antigen detection kit has been developed for the detection of Helicobacter pylori in faeces. Immunological reagents have also been combined with other diagnostic modalities to develop immunohistochemical stains and DNA immunoassays.
\end{abstract}

\section{Introduction}

Helicobacter pylori is now recognised as the cause of gastritis and most cases of peptic ulcer disease (PUD); its long term carriage increases the risk of gastric adenocarcinoma sixfold and it is designated as a class I carcinogen. ${ }^{1} \mathrm{H}$ pylori has also been implicated as a cause of gastric mucosa associated lymphoid tissue lymphomas. Its relation to non-ulcer dyspepsia remains controversial. Additionally, long term carriage of the organism may be associated with short stature in young girls and, in the general population, as a possible risk factor for the development of vasospastic disorders and possibly skin immunopathology such as urticaria. With the recognition of $H$ pylori as an important human pathogen, ${ }^{2}$ it has become one of the growing number of organisms to have its complete genome sequence mapped. ${ }^{3}$

Serology is an important method of determining colonisation status and can be used for diagnosis, as a screening procedure, or to follow the efficacy of eradication regimens. Most serological assays are in the ELISA format although some are based on the latex agglutination reaction. These latter are used principally as near patient assays. Most assays detect IgG in serum although some detect serum IgA. More recently developed assays detect IgA in saliva and the production of affinity purified antibodies has led to the development of an antigen detection assay for faecal specimens. Serological reagents have also been used in immunocytochemistry and to speed up the detection of amplified products of the polymerase chain reaction (PCR)-DNA immunoassays.

\section{Current non-invasive immunological tests}

SEROLOGY

Several different techniques exist for antibody detection. Solid phase assays are by far the most numerous and convenient. ELISA is the most often used serological format. It is usually laboratory based, requiring both some technical competence to perform and the availability of an instrument to measure the optical density of the coloured product. Alternatively, latex agglutination tests are most suitable as near patient tests because they are technically simple to perform and provide a result within minutes rather than the hour or two for ELISA tests. In the technique for simultaneously detecting a serological response to all antigens, represented by a single value of colour intensity (optical density) as in the ELISA test, both the number and intensity of staining of antibody bound protein bands or antibodies to specific antigens are taken into account. A commercial western blot test (Helicoblot 2) for the detection of $H$ pylori is also available.

\section{ELISA kits}

There have been many publications comparing either single or multiple kits $^{4-14}$ in defined populations. Tables 1 and 2 list the kits and their reported sensitivity, specificity, and positive and negative predictive values.

\section{Latex agglutination kits}

The agglutination format is not as frequently used as the ELISA format but evaluations have been published. ${ }^{15-21}$ The latex agglutination test is more convenient than the ELISA format for near patient testing and has comparable sensitivity and specificity (table 3 ).

\section{New immunological assays for $H$ pylori} HISTOLOGY

The use of stains such as the Giemsa stain to detect $H$ pylori in tissue sections relies on the experience of the histopathologist to recognise the typical morphological appearance of the organism. Clearly, small numbers of organisms may be missed. Developments of current

Abbreviations used in this paper: ELISA, enzyme linked immunosorbent assay; RIBA, recombinant immunoblot assays; PUD, peptic ulcer disease; UBT, urea breath test; RUT, rapid urease test; PCR, polymerase chain reaction. 
Table 1 Commercially produced serological assays for detection of Helicobacter pylori infection

\begin{tabular}{|c|c|c|c|}
\hline Kit name & Kit name & Test format & Manufacturer \\
\hline Pyloristat & Pylori Elisa $\mathrm{II}^{1}$ & ELISA & Biowhittaker, USA \\
\hline Pyloriset & Pyloriset update & ELISA & Orion, Finland \\
\hline Helico G & Helico G II & ELISA & Shield, UK \\
\hline Premier Hp & & ELISA & Meridian, USA \\
\hline Cobas Core & & ELISA & Roche, Switzerland \\
\hline Hel-p Test & Hel-p Test II & ELISA & Amrad, Australia \\
\hline MalaKit & & ELISA & BioLab, Belgium \\
\hline GAP IgG & GAP IgG II & ELISA & Biorad, USA \\
\hline Roche MTP & & ELISA & Roche, Switzerland \\
\hline Hp-G screen & & ELISA & Genesis, UK \\
\hline Microstar EIA & & ELISA & Kenstar, UK \\
\hline SIA Helicobacter & & ELISA & Sigma, USA \\
\hline HM-CAP EIA & & ELISA & Enteric Prod., USA \\
\hline Helisal EIA & & ELISA & Cortex, UK \\
\hline Helori CTX & & ELISA & Eurospital, Italy \\
\hline $\mathrm{H}$ pylori IgG & & ELISA & Dako, Denmark \\
\hline Autozyme & & ELISA & Cambridge LS, UK \\
\hline Pyloragen & & ELISA & Hycor, USA \\
\hline Enzygnost HP & & ELISA & Boehring, UK \\
\hline Quickvue HP EIA & & ELISA & Quidel, USA \\
\hline Enzywell HP EIA & & ELISA & Dresse Monteriggioni, Italy \\
\hline Color Vue Pylori & & ELISA & Seradyn, USA \\
\hline Autoplate & & ELISA & Menarini \\
\hline Biolife & & ELISA & Biolife \\
\hline Pyloriset & Pyloriset Dry & LA & Orion, Finland \\
\hline Helisal RBT & Helisal One Step & IMC & Cortex, UK \\
\hline Flexsure HPS & Flexsure WB & IMC & Smith-Kline, USA \\
\hline Genesis Dot & & IMC & Genesis, UK \\
\hline Quickvue One Step & & IMC & Quidel USA \\
\hline Launch Immunocard & & IMC & Meridian, USA \\
\hline Quadratech HEP & & IMC & VEDA, France \\
\hline CLOser & & IMC & Medical Inst. Corp., Switzerland \\
\hline HelicoBlot 2.0 & & WB & GeneLab, Singapore \\
\hline RIBA & & WB & Chiron, USA \\
\hline
\end{tabular}

LA, latex agglutination; IMC, immunochromatography; WB, western blotting.

Table 2 Comparison of commercially available ELISA kits for detection of Helicobacter pylori infection

\begin{tabular}{lllll}
\hline Kit name & Sensitivity (\%) & Specificity (\%) & PPV (\%) & NPV (\%) \\
\hline Pyloristat & $91-99$ & $70-94$ & 80 & 84 \\
Pylori Elisa II & 100 & 96 & 97 & 100 \\
Helico G & $71-97$ & $65-95$ & $69-90$ & $65-98$ \\
Helico G 2 & 85 & 76 & 84 & 87 \\
Premier HP & $85-100$ & $80-100$ & $76-100$ & $88-100$ \\
Cobas Core & $87-98$ & $83-98$ & 87 & 86 \\
Pyloriset & $81-97$ & $69-97$ & $76-97$ & $51-98$ \\
Pyloriset update & 100 & 79 & 95 & 100 \\
Hel-p Test & $89-100$ & $62-93$ & $65-90$ & $91-100$ \\
Malakit & $79-87$ & $86-98$ & 96 & 60 \\
GAP IgG & $76-100$ & $26-99$ & $76-100$ & $71-100$ \\
HP kit Radim & 81 & 90 & & \\
Roche MTP & $94-99$ & $83-86$ & 88 & 90 \\
HpG screen & $83-93$ & $68-91$ & $66-84$ & $84-100$ \\
Microstar & 97 & 76 & 80 & 98 \\
SIA sigma & $85-90$ & $80-98$ & $76-96$ & $88-100$ \\
HM cap EIA & $83-98$ & $80-96$ & 76 & 86 \\
Autozyme & 89 & 52 & 58 & 87 \\
Pyloragen & 79 & 75 & 71 & 83 \\
Enzygnost & 80 & 74 & 70 & 83 \\
Quidel EIA & 89 & 66 & 68 & 89 \\
Enzywell & 90 & 71 & 71 & 81 \\
Color Vue & 88 & 66 & 63 & \\
\hline
\end{tabular}

PPV, positive predictive value; NPV, negative predictive value.

Table 3 Comparison of commercially available near patient tests for detection of Helicobacter pylori infection

\begin{tabular}{lllll}
\hline Kit name & Sensitivity (\%) & Specificity (\%) & PPV (\%) & NPV (\%) \\
\hline AccuStat & 89 & 93 & 89 & 93 \\
Helisal RBT & $82-92$ & $55-91$ & $56-92$ & $86-89$ \\
FlexSure HP & $76-96$ & $77-100$ & $72-96$ & $83-95$ \\
Quick Vue & $78-89$ & $70-93$ & $70-82$ & $86-88$ \\
Pyloriset LA & $68-92$ & $56-76$ & $68-85$ & $62-84$ \\
Pyloriset Dry & $64-97$ & $75-95$ & $72-95$ & $75-93$ \\
PyloriScreen & 95 & 94 & 91 & 97 \\
HpCheck & 88 & 85 & 83 & 90 \\
Quadratech & 83 & 57 & 60 & 81 \\
CLOser & 95 & 72 & 80 & 93
\end{tabular}

PPV, positive predictive value; NPV, negative predictive value. histological methods include the use of immunohistochemistry in order to increase both the sensitivity and specificity of the method. In a comparison of immunohistochemistry, using a polyclonal antiserum, with the Giemsa and Warthin-Starry stains, the method had a higher specificity and a lower interobserver variation. ${ }^{22}$ Immunocytochemistry also performs significantly better compared with culture and biopsy urease test when small numbers of bacteria are present and following eradication treatment. ${ }^{23}$ Other histological developments include the fixing of the mucus layer using Carnoy's solution combined with immunohistochemistry, which reduces both the false positive and negative results obtained with conventional histological stains. ${ }^{24}$

PCR AND DNA-ENZYME IMMUNOASSAY

Although most diagnostic PCR amplicons are detected by gel electrophoresis, there is a growing trend towards using a colorimetric method of detection as this is more rapid and can be automated.

Three DNA enzyme immunoassays have been developed to detect $H$ pylori. The GEN-ETI-K DEIA (Sorin, Italy) uses streptavidin coated microwell plates to which is added a biotinylated specific probe based on the UreC gene of helicobacter. The amplified product is added to the plate and the duplex DNA detected with an enzyme linked antibody against double stranded DNA. PYLORIPROB (Biocode, Belgium) is a solid phase sandwich hybridisation assay. A specific capture probe (also based on the UreC gene) is bound to the microwell plate. The amplified product is added to the well and detected by a biotinylated probe to which are added streptavidin conjugated peroxidase and substrate. PCR-ELISA (Boehringer, Germany) uses a capture probe labelled with biotin (UreC) bound to the solid phase in a streptavidin coated microwell plate to which is added the amplified product labelled with digoxigenin and the hybridised product is detected with anti-digoxigenin peroxidase.

Assessment of these three kits ${ }^{25}$ was performed on biopsy specimens from 199 patients and compared with PCR with gel electrophoresis and histology/culture as a gold standard. The colorimetric DNA immunoassays were 100 times more sensitive than the standard PCR and results were obtained within four hours. The sensitivity and specificity of the three tests were $85 \%$ and $88 \%$, respectively, for GEN-ETI-K DEIA, $87 \%$ and $82 \%$ for PYLORI-PROB, and $80 \%$ and $68 \%$ for PCRELISA. The study assessed patients before and after treatment and before treatment the specificity of PYLORI-PROB and PCRELISA was only about $50 \%$. This apparent lack of specificity may highlight limitations in the "gold standard" rather than reflect on the DNA-enzyme immunoassay kits.

SEROLOGY

There are several new areas in which serological tests are being developed to detect $H$ pylori. These include the detection of IgA; virulence 
specific ELISA; immunoblot techniques; immunological tests for salivary antibodies; near patient tests; and antigen detection. Alternative formats that have been used as serological assays include flow microsphere immunofluorescence and immunochromatography, this latter for the rapid near patient testing of whole (capillary) blood. In the former, polystyrene microbeads are coated with complex antigen of $H$ pylori derived from a whole cell sonicate or urease enriched fraction. The serum containing the analyte (antibodies to $H$ pylori) is mixed with the coated microspheres and binding is detected with fluorescein isothiocyanate labelled antihuman IgG and a flow cytometer. This technique does not readily lend itself to commercialisation as not every laboratory has a flow cytometer. The principle of the immunochromatography format is binding of an antigen (in this case a purified antigen of $H$ pylori) to a membrane, addition of whole blood, and subsequent addition of anti-human IgG labelled with coloured particles. The presence of anti-H pylori antibodies in the blood is detected by a coloured spot on the membrane. An adjacent area of the membrane with bound human IgG acts as control. Alternative arrangements of this format can be used in which the antigen coated coloured particles bound to anti- $H$ pylori antibodies diffuse along the length of the membrane and are trapped by a line of antihuman IgG antibodies, thus concentrating the colour at a specific position.

Finally, isoelectric focusing can be used to investigate the serological response to infection, including that with $H$ pylori, although it is more a research method rather than a commercial test used in the management of disease. The principle is the focusing of serum antibodies to their $\mathrm{pH}$ by means of electrophoresis along a $\mathrm{pH}$ gradient, followed by transfer to a membrane loaded with antigen. Bound antibody is detected in a fashion similar to that of western blotting. Using this technique one can detect a monoclonal, oligoclonal, or polyclonal response representing the cellular dynamics of antibody production.

Serum antibody assays

Assays for IgA have been neglected in favour of IgG. However, some commercial kits do assess serum IgA and in one study of 400 patients the sensitivity and specificity of the IgA assay was comparable with that of IgG. ${ }^{26}$ Whether IgA levels give any clinical advantage over IgG is currently unknown.

The detection of CagA and VacA by ELISA or immunoblotting may provide additional information which could be of clinical relevance. Infection by $\mathrm{Cag}$ and Vac positive strains (type I strains) is generally more likely to be associated with more serious gastroduodenal disease compared with negative (type II) strains. This association, however, is not seen in all countries. In one study of 98 patients detection of $125 \mathrm{kDa}$ (Cag), $87 \mathrm{kDa}$ (Vac), and a hitherto unidentified $35 \mathrm{kDa}$ component of helicobacter was correlated with ulcer disease. ${ }^{27}$
Salivary antibody assay

Because of the ease of collection, particularly in children, salivary antibody assays may be particularly useful. In one study of 157 patients referred for investigation of dyspepsia, using the Helisal (Cortex) salivary kit, the positive predictive value was very low (sensitivity $85 \%$; specificity $55 \%$; positive predictive value $45 \%$; negative predictive value $90 \%$ ) when compared with histology in a population in which the prevalence of helicobacter infection was $30 \% .{ }^{28}$ Similarly, in a study of 86 patients when compared with culture, histology, and the rapid urease test (RUT), the Helisal kit had a sensitivity and specificity of $88 \%$ and $71 \%$, respectively, but was inferior to assessment on serum. ${ }^{29}$

Using the OraSure salivary device (Epitope Inc.) to collect salivary antibodies from 100 children, sensitivity and specificity of $100 \%$ and $61 \%$, respectively, were obtained with positive and negative predictive values of $100 \%$ and $92 \%$ when compared with a urea breath test (UBT). ${ }^{30}$ Similarly good results were obtained in another study using the OraSure test. In this study, ${ }^{31} 740$ children were tested with the saliva collected by the OraSure device and the serology performed by HM-CAP EIA (Enteric Products), giving a sensitivity and specificity of $85 \%$ and $93 \%$. These results are encouraging and with further development salivary antibody tests may be of diagnostic utility.

\section{Western blotting and CagA ELISA}

Because western blotting determines the serological response to a range of antigens from an organism, it could provide more information than an ELISA. Initial studies showed that serological response to certain antigens was strongly correlated with infection and in particular the $120-138 \mathrm{kDa}$ CagA protein was associated with PUD and gastric cancer. In one study, comparing immunoblotting with an in-house ELISA and a commercial ELISA (Color Vue EIA) that uses an unspecified purified antigen, western blotting was more sensitive and specific than the enzyme immunoassays $^{28}$ and serological reactions to specific proteins - for example, CagA could be detected. CagA is a highly immunogenic protein whose function is unknown. It is only present in about $50-60 \%$ of strains; the presence of CagA in a strain is correlated with increased interleukin 8 secretion by the gastric epithelium and is possibly associated with the presence of PUD and gastric cancer, at least in some populations. The detection of a serological response may therefore give clinically relevant information about the infecting strain. Western blotting has been developed into commercial kits, Helico-blot 2.0 and RIBA strip; the latter identifies immunological response to recombinant CagA and VacA proteins. In a large study of over 3000 subjects, ${ }^{32}$ the RIBA results were compared with ${ }^{13} \mathrm{C}$-UBT and western blotting and had a sensitivity and specificity of $92 \%$. Furthermore, a positive reaction to the lysate or Cag and Vac correlated with current infection, but a positive result with 
either Cag or Vac alone indicated a past infection. In some studies, however, serological detection of antibodies to Cag was no better than detection of anti-helicobacter antibodies. ${ }^{33}$ In a comparison of Helicoblot 2, RIDA Blot Helicobacter, and RIBA HP SIA, the positive and negative predictive values for diagnosis of colonisation were $97 \%$ and $90 \%$ (HelicoBlot 2); 94\% and 92\% (RIDA), and $98 \%$ and $85 \%$ (RIBA). For CagA status, however, the positive and negative predictive values were, respectively, 96\% and 55\% (HelicoBlot), $94 \%$ and $100 \%$ (RIDA), and $95 \%$ and $55 \%$ (RIBA); and for VacA status, $100 \%$ and $46 \%$ (HelicoBlot), $78 \%$ and $100 \%$ (RIDA), and $95 \%$ and $76 \%$ (RIBA). Significant false positive and negative results were obtained. When used for pre-endoscopy screening the tests missed a significant number of patients with serious pathology. ${ }^{34}$

Near patient tests

There is an increasing requirement for near patient testing as more patients are managed by general practitioners on a test and treat basis. Several new near patient tests are available but generally they lack diagnostic accuracy when compared with laboratory ELISAs. Most of the tests are one step tests using whole blood but others require serum separation, which diminishes their usefulness as near patient kits. Also, with one test kit, variations in sensitivity and specificity were noted depending on whether capillary or venous blood was used. Helisal Rapid blood test had a sensitivity and specificity of $88 \%$ and $91 \%$, and positive and negative predictive values of $92 \%$ and $86 \%$ when compared with histology, culture, RUT, and ${ }^{13} \mathrm{C}$-UBT in 154 dyspeptic patients. ${ }^{35}$ These results compared with $93 \%$ and $87 \%$ sensitivity and specificity for an ELISA test (Helico G) in 109 of the patients. Another assessment on 203 patients, ${ }^{36}$ compared with RUT/histology, gave a sensitivity and specificity of $82 \%$ and $91 \%$; in this study there was concurrence of results whether venous or capillary blood was used. When Helisal was compared with a laboratory ELISA its sensitivity and specificity were $83 \%$ and $78 \% .^{37}$ Other studies have found much lower specificity (55\%) when compared with RUT/histology/culture. ${ }^{38}$ In a study of 200 patients, although the sensitivity was high (91$92 \%)$ the specificity was low $(56-62 \%) .{ }^{39}$ In a study comparing Helisal with the UBT on 351 patients the specificity of the near patient test was poor compared with the UBT and the specificity of the kit decreased with increasing age of the patient. ${ }^{40}$

A study of the accuracy of a new rapid whole blood test kit Pyloriset Screen, compared with Pyloriset EIA and Pyloriset Dry, on 207 patients showed it had a sensitivity and specificity of $95 \%$ and $94 \%$, respectively, with positive and negative predictive values of $91 \%$ and $97 \%{ }^{41}$ The QuickVue one step blood test had a sensitivity and specificity of $82 \%$ and $83 \%$ in a retrospective analysis of 193 patients and $89 \%$ and $93 \%$ in a prospective study on 24 patients. If venous blood was used rather than capillary blood the sensitivity decreased to
$73 \% .^{42} \mathrm{Hp}$ Chek was tested on 287 patients in 10 centres in the USA and gave a result within nine minutes. The results were similar if whole blood or serum was used and the sensitivity, specificity, and positive and negative predictive values were $88 \%, 85 \% 83 \%$, and $90 \%$, respectively. Rapid immunochromatographic tests are also available. In a study of 1209 samples from children, the sensitivity and specificity of FlexSure HP were $83-90 \%$ and $90-100 \%$, respectively, but the positive predictive value was low in asymptomatic children compared with that of an ELISA test. ${ }^{43}$ However, a further study found FlexSure to have a positive predictive value of $88 \%$ which was equivalent to a laboratory based ELISA result. ${ }^{44}$

Interlaboratory and intralaboratory comparisons have not yet been performed and published for these kits and a recent publication does not support the use of these kits as presently formulated for near patient testing. ${ }^{45}$

\section{Antigen detection}

One of the most promising developments for the detection of $H$ pylori is faecal antigen detection because of its speed, technical simplicity, and ease of sample collection. The Premier platinum HpSA EIA (Meridian Diagnostics, USA) uses an affinity purified polyclonal antibody attached to microwell plates to which is added a faecal suspension followed by a peroxidase conjugated antibody and substrate. This kit has been assessed in several studies. In a European multicentre study from 12 participating centres, 501 patients were analysed and the efficacy compared with histology, RUT, culture, and UBT. ${ }^{46}$ The sensitivity and specificity were reported as $94 \%$ and $91 \%$, respectively, with positive and negative predictive values of $93 \%$ and $92 \%$ in a population where the overall prevalence was $55 \%$ helicobacter positive. A smaller number of patients was studied four weeks after the end of eradication treatment and gave a sensitivity and specificity of $100 \%$ and $90 \%$. The faecal antigen kit has been tested in other studies, ${ }^{47-49}$ all giving comparable sensitivities and specificities $(91-98 \%$ and $83-96 \%)$. After treatment, the antigen seems to disappear quite rapidly (within a few days) from the faeces ${ }^{50}$ but the specificity was recorded as $79 \%{ }^{47}$ However, in a further study comparing $\mathrm{HpSA}$ with PCR, antigen and DNA were still detectable in the faeces 35 days after treatment. ${ }^{5}$ Further development of the test is likely to improve its utility in monitoring eradication treatment. An emerging potential useful method in addition to antigen or DNA detection is the use of immunomagnetic beads to isolate the organism.

\section{Conclusions}

Although there are many well validated methods that can be used to detect $H$ pylori, there are nevertheless continued improvements to current tests and the development of new tests, driven by considerations of cost and a search for speed and technical simplicity. An increasing number of patients may be treated by their general practitioners and consequently there is 
a requirement for a rapid, simple, accurate, near patient test. Furthermore, the emergence of antibiotic resistant isolates has given an impetus to the development of rapid molecular techniques to identify such resistant organisms. The current main areas of development in diagnostic tests are in the use of non-invasive salivary antibody and faecal antigen tests, the use of rapid near patient antibody tests, and the development of DNA immunoassays for the detection of both antibiotic sensitive and resistant $H$ pylori.

1 National Institute of Health Consensus Conference. Helicobacter pylori in peptic ulcer disease fAMA 1994;272:65-9.

2 IARC. Schistosomes, liver fluke and $H$. pylori. IARC monograph on the evolution of carcinogen risks in humans. Lyon: International Agency for Research on Cancer, 1994 61:177-240

3 Tomb JF, White O, Kerlavage AR, et al. The complete genome sequence of the gastric pathogen Helicobacter pylori. Nature 1997;388:539-47.

4 van den Oever HL, Loffeld RJ, Stobberingh EE. Uselfuness of a new serological test (BIORAD) to diagnose Helicobacter pylori-associated gastritis. f Clin Microbiol 1991;29. 283-6.

5 Goossens H, Glupczynski Y, Burette A, et al. Evaluation of a commercially available complement fixation test for diagnosis of Helicobacter pylori infection and for follow-up after antimicrobial therapy. F Clin Microbiol 1992;30:32303 .

6 Aguirre PM, Pascual CY, Merino FJ, et al. Evaluation of two commercial enzyme immunoassays for the diagnosis of Helicobacter pylori infection. Eur f Clin Microbiol Infect Di 1992;11:634-9.

7 Trautmann M, Moldrzyk M, Vogt K, et al. Use of a receiver operating characteristic in the evaluation of two commercial enzyme immunoassays for detection of Helicobacter pylori infection. Eur 7 Clin Microbiol Infect Dis 1994;13: 812-19.

8 Granberg C, Mansikka A, Lehtonen OP, et al. Diagnosis of Helicobacter pylori infection by using pyloriset EIA-G and EIA-A for detection of serum immunoglobulin G (IgG) and IgA antibodies. F Clin Microbiol 1993;31:1450-3.

9 Raymond J, Kalach N, Bergeret M, et al. Evaluation of a serological test for diagnosis of Helicobacter pylori
infection in children. Eur $\mathcal{F}$ Clin Microbiol Infect Dis infection in child

10 Marchildon PA, Ciota LM, Zamaniyan FZ, et al. Evaluation of three commercial enzyme immunoassays compared with ${ }^{13} \mathrm{C}$ urea breath test for detection of Helicobacter pylor infection. F Clin Microbiol 1996;34:1147-52.

11 Talley NY, Kost L, Haddad A, et al. Comparison of commercial serological tests for detection of Helicobacter pylori antibodies. F Clin Microbiol 1992;30:3146-50.

12 van de Wouw BA, de Boer WA, Jansz AR, et al. Comparison of three commercially available enzyme linked immunosorbent assays and biopsy dependent diagnosis for detecting Helicobacter pylori infection. $f$ Clin Microbiol 1996;34:94-7.

13 Wilcox MH, Dent TH, Hunter JO, et al. Accuracy of serology for the diagnosis of $\mathrm{H}$ pylori infection: a comparison of eight commercially available $\mathrm{H}$ pylori serology kits. $\mathcal{F}$ Clin Pathol 1996;49:373-6.

14 Feldman RA, Deeks JJ, Evans SJW, et al. Multi-laboratory comparison of eight commercially available $\mathrm{H}$ pylori serology kits. Eur $\mathcal{F}$ Clin Microbiol Infect Dis 1995;14:428-33.

15 Lozniewski A, de Korwin JD, Conroy MC, et al. Evaluation of Pyloriset Dry, a new agglutination test for $\mathrm{H}$ pylori antibody detection. F Clin Microbiol 1996;31:1773-5.

16 Hirschl AM, Hirschl MM, Berger J, et al. Evaluation of a commercial latex test for the serological diagnosis of $\mathrm{H}$ pylori infections in treated and untreated patients. Eur $\mathcal{F}$ Clin Microbiol Infect Dis 1991;10:971-4.

17 Hoek FJ, Noach LA, Rauws AJ, et al. Evaluation of the performance of commercial test kits for detection of $\mathrm{H}$ pylor
antibodies in serum. $\mathcal{F}$ Clin Microbiol 1992;30:1525-8.

18 Jensen AKV, Andersen LP, Wachmann CH. Evaluation of eight commercial kits for $\mathrm{H}$ pylori IgG antibody detection. APMIS 1993;101:795-801.

19 Midolo PD, Lambert JR, Russell EG, et al. A practical single sample dry latex agglutination test for $\mathrm{H}$ pylori antibody detection. F Clin Pathol 1995;48:969-71.

20 Schembri MA, Lin SK, Lambert JR. Comparison of commercial diagnostic tests for $\mathrm{H}$ pylori antibodies. $\mathcal{F}$ Clin Microbiol 1993;31:2621-4.

21 Westblom TU, Madan E, Gudipati S, et al. Diagnosis of $\mathrm{H}$ pylori infection in adults and paediatric patients by using Pyloriset, a rapid latex agglutination test. F Clin Microbio

22 Jonkers D, Stobberingh E, de-Bruine A, et al. Evaluation of immunohistochemistry for the detection of Helicobacter
pylori in gastric mucosal biopsies. F Infect 1997;35:149-54.
23 Marzio L, Angelucci D, Grossi L, et al. Anti-Helicobacter pylori specific antibody immunohistochemistry improves specimens from patients treated with triple therapy. $\operatorname{Am} \mathcal{F}$ specimens from patients treated

24 Misaka K, Kumagai T, Shimizu T, et al. A new histological procedure for re-evaluation of the serological tests for Helicobacter pylori. Eur F Clin Microbiol Infect Dis 1998;17: $14-19$.

25 Monteiro L, Cabrita J, Megraud F. Evaluation of performances of three DNA-enzyme immunoassays for detection of Helicobacter pylori PCR products from biopsy specimens. F Clin Microbiol 1997;35:2931-6.

26 Martin de Argila C, Boixeda D, Canton R, et al. Usefulness of the combined IgG and IgA antibody determinations for serodiagnosis of Helicobacter pylori infection. Eur $\mathcal{F}$ Gastroenterol Hepatol 1997;9:1191-6.

27 Aucher P, Petit ML, Mannant PR, et al. Use of immunoblot assay to define serum antibody patterns associated with Helicobacter pylori infection and with $\mathrm{H}$. pylori-related ulcers. F Clin Microbiol 1998;36:931-6.

28 Loeb MB, Riddell RH, James C, et al. Evaluation of salivary antibodies to detect infection with Helicobacter pylori. Can I Gastroenterol 1997;11:437-40.

29 Christie JM, McNulty CA, Shepherd NA, et al. Is saliva serology useful for the diagnosis of Helicobacter pylori. Gut 1996;39:27-30.

30 Malaty HM, Peacock JS, Marchildon P, et al. OraSure salivary test for the screening of Helicobacter pylori infection in asymptomatic children [abstract]. Gut 1998;43(suppl 2):A53.

31 Passaretti N, Mina T, White E, et al. Evaluation of the diagnostic utility in children of a salivary EIA to detect IgG antibodies to H. pylori [abstract]. Gut 1998;43(suppl 2):A54.

32 Vaira D, Fusconi $M$, Menegatti $M$, et al. A novel recombinant immunoblotting assay (RIBA) for determination of serological reactivities of Helicobacter pylori (HP) [abstract]. Gut 1997;41:A77.

33 Yamaoka Y, Kodama T, Graham DY, et al. Comparison of four serological tests to determine the CagA or VacA status our serological tests to determine the CagA or VacA status of Helico

34 Heikkinen M, Janatuinen E, Mayo K, et al. Usefulness of anti-Helicobacter pylori and anti-CagA antibodies in the selection of patients for gastroscopy. Am f Gastroenterol 1997;92:2225-9.

35 Moayyedi P, Carter AM, Catto A, et al. Validation of a rapid whole blood test for diagnosing $\mathrm{H}$. pylori infection. $B M \mathcal{F}$ 1997;314:119.

36 Borody TJ, Andrews P, Shortis NP. Evaluation of whole blood antibody kit to detect active H. pylori infection. Am f Gastroenterol 1996;91:2509-12.

37 Jones R, Phillips I, Felix G, et al. An evaluation of near patient testing for $\mathrm{H}$. pylori in general practice. Aliment Pharmacol Ther 1997;11:101-5.

38 Stevens M, Livsey SA. MDA evaluation reports. Nos 15, 16, 17, 37, 43. Norwich: HMSO, 1997.

39 Stone MA, Mayberry JF, Wicks AC, et al. Near patient testing for Helicobacter pylori: a detailed evaluation of the Cortecs Helisal Rapid Blood test. Eur $\mathcal{F}$ Gastroenterol Hepatol 1997;9:257-60.

40 Mowat C, Murray L, Hilditch TE, et al. Comparison of helisal rapid blood test and 14C-urea breath test in determining Helicobacter pylori status and predicting ulcer disease in dyspeptic patients. Am $\mathcal{F}$ Gastroenterol 1998;93: $20-5$.

41 Oksanen A, Veijola L, Sipponen P, et al. Evaluation of Pyloriset Screen, a rapid whole-blood diagnostic test for Helicobacter pylori infection. F Clin Microbiol 1998;36: 955-7.

42 Duggan AE, Hardy E, Hawkey CJ. Evaluation of a new near patient test for the detection of Helicobacter pylori. Eur $\mathcal{F}$ Gastroenterol Hepatol 1998;10:133-6.

43 Elitsur Y, Neace C, Triest WE. Comparison between a rapid office-based and ELISA serologic test in screening for Helicobacter pylori in children. Helicobacter 1997;2:180-4.

44 Anderson JC, Cheng E, Roeske M, et al. Detection of serum antibodies to Helicobacter pylori by an immunochromatographic method. Am f Gastroenterol 1997;92:1135-9.

45 Anon J. Helicobacter pylori testing kits. Drugs and Therapeutics 1997;35:23-4

46 Vaira D, Malfertheiner P, Megraud F, et al. A novel antigen assay based on a stool specimen for Helicobacter pylori: European multicentre study [abstract]. Gut 1998;43 (suppl 2):A47

47 Trevisani L, Sartori S, Galvani F, et al. Evaluation of a new enzyme immunoassay for detecting Helicobacter pylori in faeces [abstract]. Gut 1998;43(suppl 2):A47.

48 Veldhuyzen van Zantan S, Bleau BL, Best L, et al. Use of the Helicobacter pylori stool antigen test (HPSAT) for detection of H. pylori infection. Gut 1998;43(suppl 2):A49.

49 Forne $M$, Dominguez J, Esteve $M$, et al. Detection of Helicobacter pylori antigen in stool specimens in the diagnosis of infection and post treatment check-up. Preliminary results [abstract]. Gut 1998;43(suppl 2):A50.

50 van't Hoff BWM, van der Ende A, van der Hulst RWM, et al. Helicobacter pylori antigen in stool specimen as a possi1998;43(suppl 2):A49.

51 Makristathis A, Pasching E, Schultz K, et al. Detection of Helicobacter in stool specimens by PCR and antigen EIA [abstract]. Gut 1998;43(suppl 2):A47. 